\title{
Availability of a Redundant System with Two Parallel Active Components
}

\author{
Yutae Lee \\ Department of Information and Communications Engineering, Dongeui University
}

\begin{abstract}
-
This paper considers a redundant system which consists of two parallel active components. The time-to-failure and the time-to-repair of the components follow an exponential and a general distribution, respectively. The repairs of failed components are randomly interrupted. The time-to-interrupt is taken from an exponentially distributed random variable and the interrupt times are generally distributed. We obtain the availability for the system.
\end{abstract}

Keywords: Active component, availability, parallel system, redundancy

Date of Submission: 10 February $2017 \quad$ Date of Accepted: 25 February 2017

\section{INTRODUCTION}

Availability is defined as the probability that a system is operational at a given point in time under a given set of environmental conditions. There have been efforts to improve the availability. Redundant systems are typically used to improve the availability.There are various redundant systems to appropriately support uptime requirements in the industry.

The availability analysis of a system is based on analyzing the various states that the system undergoes during its lifespan. Since the occurrence of failures is erratic by nature, stochastic models have been used to conduct the availability analysis.Markov models have been extensively used, because of their expressiveness and their capability of capturing the complexity of real systems[1,2,3,4]. A major problem of Markov models is that a large number of states are required to represent the model accurately [1]. Kanso et al. [5] used stochastic reward nets(SRNs) and evaluated the availability by the analytic-numeric methods of stochastic Petri net package (SPNP). Kim et al. [6] analyzed the networking service availability of $2 \mathrm{~N}$ redundant system with non-stop forwarding by using the SPNP. The analytic-numeric methods of SPNP provide the capabilities of solving the Markov SRNs but fail for non-Markov SRNs.Kuznetsov[7] evaluated the availability of repairable networks with general repair time distribution by fast simulation method.

The most existing literature has focused on uninterrupted repairs with exponentially distributed repair time.Kuo and $\mathrm{Ke}[8]$ studied the availability of a series system with interrupted repairs and generally distributed repair time.Bosse et al. [9] estimated the availability of a redundant system with imperfect switchovers and interrupted repairs by using a Petri net Monte Carlo simulation.Lee [10] analyzed the availability of a system with one active and one standby component.In this paper, we focus on the availability for a parallel redundant system with two active components, generally distributed repair times, and interrupted repairs.

\section{MODEL}

This paper considers a redundant system withtwo parallel active components.It is assumed that each component fails independently of the state of the other. Let the time-to-failure of the active components be exponentially distributed with rate $\lambda$. The repair time $X$ is generally distributed with probability density function (PDF) f(x) and cumulative distribution function (CDF) $\mathrm{F}(\mathrm{x})$. Moreover, the repairer may function wrongly or fail sometimes in its busy period with an exponential failure rate $\delta$. Once the repairer becomes available again, it resumes the interrupted process. The interrupted time $\mathrm{Z}$ is generally distributed with PDF $\mathrm{h}(\mathrm{z})$ and $\mathrm{CDF} \mathrm{H}(\mathrm{z})$.

The random process $X_{-}(t)$ denotes the amount of repair already received by a failed component in repair at time $t$. The random variable $Z_{-}(t)$ denote the elapsed interrupted time at time $t$. We also introduce:

$$
\begin{aligned}
& \alpha(\mathrm{x}) \equiv \frac{\mathrm{f}(\mathrm{x})}{1-\mathrm{F}(\mathrm{X})} \\
& \gamma(\mathrm{z}) \equiv \frac{\mathrm{h}(\mathrm{x})}{1-\mathrm{H}(\mathrm{X})}
\end{aligned}
$$




\section{AVAILABILITY}

Let $\mathrm{N}(\mathrm{t})$ be the number of active components at time t.Let us define:

$$
\begin{aligned}
& \mathrm{P}_{0}(\mathrm{x}, \mathrm{z}) \mathrm{dxdz} \equiv \lim _{\mathrm{t} \rightarrow \infty} \mathrm{P}\left\{\mathrm{N}(\mathrm{t})=0, \mathrm{x}<\mathrm{X}_{-}(\mathrm{t})<x+d x, z<\mathrm{Z}_{-}(\mathrm{t})<z+d z\right\} \\
& \mathrm{P}_{1}(\mathrm{x}, \mathrm{z}) \mathrm{dxdz} \equiv \lim _{\mathrm{t} \rightarrow \infty} \mathrm{P}\left\{\mathrm{N}(\mathrm{t})=1, \mathrm{x}<\mathrm{X}_{-}(\mathrm{t})<x+d x, z<\mathrm{Z}_{-}(\mathrm{t})<z+d z\right\} \\
& \mathrm{Q}_{0}(\mathrm{x}) \mathrm{dx} \equiv \lim _{\mathrm{t} \rightarrow \infty} \mathrm{P}\left\{\mathrm{N}(\mathrm{t})=0, \mathrm{x}<\mathrm{X}_{-}(\mathrm{t})<x+d x\right\} \\
& \mathrm{Q}_{1}(\mathrm{x}) \mathrm{dx} \equiv \lim _{\mathrm{t} \rightarrow \infty} \mathrm{P}\left\{\mathrm{N}(\mathrm{t})=1, \mathrm{x}<\mathrm{X}_{-}(\mathrm{t})<x+d x\right\} \\
& \mathrm{Q}_{2} \equiv \lim _{\mathrm{t} \rightarrow \infty} \mathrm{P}\{\mathrm{N}(\mathrm{t})=2\} \\
& \mathrm{P}_{\mathrm{n}} \equiv \int_{0}^{\infty} \mathrm{P}_{\mathrm{n}}(\mathrm{x}, \mathrm{z}) \mathrm{dxdz}, \mathrm{n}=0,1 \\
& \mathrm{Q}_{\mathrm{n}} \equiv \int_{0}^{\infty} \mathrm{Q}_{\mathrm{n}}(\mathrm{x}) \mathrm{dx}, \mathrm{n}=0,1
\end{aligned}
$$

We construct the following equations governing the steady-state behavior of the system:

$$
\begin{aligned}
& \frac{\mathrm{dP}_{0}(\mathrm{x}, \mathrm{z})}{\mathrm{dz}}=-\gamma(\mathrm{z}) \mathrm{P}_{0}(\mathrm{x}, \mathrm{z})+\lambda \mathrm{P}_{1}(\mathrm{x}, \mathrm{z}) \\
& \frac{\mathrm{dP}_{1}(\mathrm{x}, \mathrm{z})}{\mathrm{dz}}=-[\lambda+\gamma(\mathrm{z})] \mathrm{P}_{1}(\mathrm{x}, \mathrm{z}) \\
& \frac{\mathrm{dQ}_{0}(\mathrm{x})}{\mathrm{dx}}=-[\delta+\alpha(\mathrm{x})] \mathrm{Q}_{0}(\mathrm{x})+\lambda \mathrm{Q}_{1}(\mathrm{x})+\int_{0}^{\infty} \gamma(\mathrm{z}) \mathrm{P}_{0}(\mathrm{x}, \mathrm{z}) \mathrm{dz} \\
& \frac{\mathrm{dQ}_{1}(\mathrm{x})}{\mathrm{dx}}=-[\lambda+\delta+\alpha(\mathrm{x})] \mathrm{Q}_{1}(\mathrm{x})+\int_{0}^{\infty} \gamma(\mathrm{z}) \mathrm{P}_{1}(\mathrm{x}, \mathrm{z}) \mathrm{dz} \\
& 0=-2 \lambda \mathrm{Q}_{2}+\int_{0}^{\infty} \alpha \mathrm{Q}_{1}(\mathrm{x}) \mathrm{dx}
\end{aligned}
$$

with boundary conditions:

$\mathrm{P}_{\mathrm{n}}(\mathrm{x}, 0)=\delta \mathrm{Q}_{\mathrm{n}}(\mathrm{x}), \mathrm{n}=0,1$

$\mathrm{Q}_{0}(0)=0$

$\mathrm{Q}_{1}(0)=2 \lambda \mathrm{Q}_{2}+\int_{0}^{\infty} \alpha \mathrm{Q}_{0}(\mathrm{x}) \mathrm{dx}$

Solving (10) and (11) with the above conditions, we obtain:

$\mathrm{P}_{1}(\mathrm{x}, \mathrm{z})=\delta \mathrm{e}^{-\lambda \mathrm{z}} \overline{\mathrm{H}}(\mathrm{z}) \mathrm{Q}_{1}(\mathrm{x})$

$\mathrm{P}_{0}(\mathrm{x}, \mathrm{z})=\delta \overline{\mathrm{H}}(\mathrm{z})\left[\left(1-\mathrm{e}^{-\lambda \mathrm{z}}\right) \mathrm{Q}_{1}(\mathrm{x})+\mathrm{Q}_{0}(\mathrm{x})\right]$

where $\bar{H}(\mathrm{z})=1-\mathrm{H}(\mathrm{z})$. From (12) and (13)with (18), (19), and the boundary conditions, we get:

$$
\begin{aligned}
& \mathrm{Q}_{1}(\mathrm{x})=\mathrm{e}^{-\left[\lambda+\delta-\delta \mathrm{h}^{*}(\lambda)\right] \mathrm{x}} \overline{\mathrm{F}}(\mathrm{x}) \mathrm{Q}_{1}(0) \\
& \mathrm{Q}_{0}(\mathrm{x})=\left[1-\mathrm{e}^{-\left[\lambda+\delta-\delta \mathrm{h}^{*}(\lambda)\right] \mathrm{x}}\right] \overline{\mathrm{F}}(\mathrm{x}) \mathrm{Q}_{1}(0)
\end{aligned}
$$

where $\bar{F}(y)=1-F(y)$ and $h^{*}(s)$ is the Laplace Stieljes Transform (LST) of $h(t)$. From (14) and (20):

$$
\mathrm{Q}_{2}=\frac{\mathrm{f}^{*}\left(\lambda+\delta-\delta \mathrm{h}^{*}(\lambda)\right)}{2 \lambda} \mathrm{Q}_{1}(0)
$$

wheref* $(s)$ is the LST of $f(t)$.Thus, $Q_{n}(x), Q_{2}$, and $P_{n}(x, z)$ can be expressed by $Q_{1}(0)$.After some manipulations, we obtain:

$$
\begin{aligned}
& \mathrm{Q}_{0}=\left[\mathrm{E}(\mathrm{X})-\overline{\mathrm{F}}^{*}\left(\lambda+\delta-\delta \mathrm{h}^{*}(\lambda)\right)\right] \mathrm{Q}_{1}(0) \\
& \mathrm{Q}_{1}=\overline{\mathrm{F}}^{*}\left(\lambda+\delta-\delta \mathrm{h}^{*}(\lambda)\right) \mathrm{Q}_{1}(0) \\
& \mathrm{Q}_{2}=\frac{\mathrm{f}^{*}\left(\lambda+\delta-\delta \mathrm{h}^{*}(\lambda)\right)}{2 \lambda} \mathrm{Q}_{1}(0) \\
& \mathrm{P}_{0}=\delta \mathrm{E}(\mathrm{Z}) \mathrm{Q}_{0}+\delta\left[\mathrm{E}(\mathrm{Z})-\overline{\mathrm{H}}^{*}(\lambda)\right] \mathrm{Q}_{1} \\
& \mathrm{P}_{1}=\delta \overline{\mathrm{H}}^{*}(\lambda) \mathrm{Q}_{1}
\end{aligned}
$$


where $\overline{\mathrm{F}}^{*}(\mathrm{~s})$ and $\overline{\mathrm{H}}^{*}(\mathrm{~s})$ are the LSTs of $\overline{\mathrm{F}}(\mathrm{t})$ and $\overline{\mathrm{H}}(\mathrm{t})$, respectively.By the normalization condition:

$$
\mathrm{Q}_{1}(0)=\frac{2 \lambda}{2 \lambda \mathrm{E}(\mathrm{X})[1+\delta \mathrm{E}(\mathrm{Z})]+\mathrm{f}^{*}\left(\lambda+\delta-\delta \mathrm{h}^{*}(\lambda)\right)}
$$

Then, the availability Av can be obtained as:

$$
\mathrm{Av}=\frac{\mathrm{f}^{*}\left(\lambda+\delta-\delta \mathrm{h}^{*}(\lambda)\right)+2 \lambda\left[1+\delta \overline{\mathrm{H}}^{*}(\lambda)\right] \overline{\mathrm{F}}^{*}\left(\lambda+\delta-\delta \mathrm{h}^{*}(\lambda)\right)}{2 \lambda \mathrm{E}(\mathrm{X})[1+\delta \mathrm{E}(\mathrm{Z})]+\mathrm{f}^{*}\left(\lambda+\delta-\delta \mathrm{h}^{*}(\lambda)\right)}
$$

\section{CONCLUSION}

By using supplementary variables, we have obtained the analytical expression of the steady-state availability for a redundancy model with two parallel active components. The time-to-failure and the time-to-repair of the components follow an exponential and a general distribution, respectively. The repairs of failed components are randomly interrupted. The time-to-interrupt is taken from an exponentially distributed random variable and the interrupt times are generally distributed.

\section{ACKNOWLEDGEMENT}

This work was supported by the ICT R\&D program of MSIP/IITP. [R0101-15-0070, Development of The High Availability Network Operating System for Supporting Non-Stop Active Routing].

\section{REFERENCES}

[1]. G. Ambuj and L. Stephen, Modeling and analysis of computer system availability, IBM Journal of Research and Development,31(6), 1987, 651-664.

[2]. K.H. Wang and B.D. Sivazlian, Reliability of a system with warm standbys and repairmen, Microelectronic and Reliability, 29, 1989, $849-860$

[3]. A. Wood, Availability modeling, Circuits and Devices Magazine, IEEE, 10(3), 1994, 22-27.

[4]. K.H. Wang and J.C. Ke, Probabilistic analysis of a repairable system with warm standbys plus balking and reneging, Applied mathematical Modelling, 27, 2003, 327-336.

[5]. A. Kanso, F. Khendek, A. Mishra, and M. Toeroe, Integrating legacy applications for high availability: a case study, Proc. 13th IEEE International Symposium on High-Assurance Systems Engineering, 2011, 83-90.

[6]. D. Kim, J. Shim, H. Ryu, and Y. Lee, Networking service availability analysis of $2 \mathrm{~N}$ redundancy model with non-stop forwarding, Lecture Notes in Electrical Engineering, 339, 2015, 1063-1069.

[7]. N.Y. Kuznetsov, Evaluation of the reliability of repairable (s-t) networks by fast simulation method, Journal of Automation and Information Sciences, 46(5), 2014, 1-14.

[8]. C.C. Kuo and J.C. Ke, Comparative analysis of standby systems with unreliable server and switching failure, Reliability Engineering and System Safety, 145, 2016, 74-82.

[9]. S. Bosse, M.Splieth, and K. Turowski, Multi-objective optimization of IT service availability and costs, Relib. Eng. Syst. Saf., 147, 2016, 142-155.

[10]. Y. Lee, Availability analysis of redundancy model with generally distributed repair time, imperfect switchover, and interrupted repair, Electronics Letters, 52(22), 2016, 1851-1853 